\title{
Preventing neural tube defects in Europe: population based study
}

Araceli Busby, Lenore Abramsky, Helen Dolk, Ben Armstrong, a Eurocat Folic Acid Working Group

London School of Hygiene and Tropical Medicine, London

WC1E 7HT

Araceli Busby lecturer in environmental epidemiology Ben Armstrong reader in statistics

North Thames (West) Congenital Malformations Register, Northwick Park Hospital, Harrow, Middlesex HA1 3UJ Lenore Abramsky registry leader

EUROCAT Central Registry, University of Ulster,

Newtownabbey, Co Antrim, Northern Ireland BT37 OQB

Helen Dolk professor of epidemiology

Corresponding author: A Busby araceli.busby@ lshtm.ac.uk

BMJ 2005;330:574-5
Each year, more than 4500 pregnancies in the European Union are affected by neural tube defects. Unambiguous evidence of the effectiveness of periconceptional folic acid in preventing neural tube defects has been available since $1991,{ }^{1}$ and improving folate status sufficiently could result in the prevention of more than two thirds of all neural tube defects. We report on trends in the prevalence of neural tube defects up to 2001, in the context of a survey in 16 European countries of periconceptional folic acid policies and their implementation..$^{23}$

\section{Participants, methods, and results}

Eurocat is a network of population based congenital anomaly registries in Europe (www.eurocat.ulster. ac.uk). A total of 9273212 births were surveyed by 31 registries in 16 countries 1980-2001, ${ }^{3}$ including 8913 babies or fetuses with neural tube defects (anencephaly, spina bifida, or encephalocele): 3298 live births, 844 stillbirths, and 4771 terminations of pregnancy after prenatal diagnosis. In the United Kingdom and Ireland, yearly prevalence of neural tube defects declined, predating any periconceptional folic acid supplementation policy initiatives, from 45 per 10000 births in 1980 to 10 to 15 per 10000 in the 1990 s (figure). In contrast, in the rest of Europe the prevalence during the 1980 s and thereafter was close to 10 per 10000 births (figure).

The first governments to formulate a periconceptional folic acid supplementation policy were the United Kingdom (1992), Ireland (1993), and the Netherlands (1993); six more (Switzerland 1996, Denmark 1997, Norway 1998, Portugal 1998, France 2000, and Spain 2001) followed. Malta (1994) and Finland (1995) recommended raising folate status by dietary means only. Austria, Belgium, Croatia, Germany, and Italy had no government policy, although in all these countries professional bodies have issued guidelines or recommendations. ${ }^{2}$

For 23 of the registers with data going back to at least 1990, we compared changes in prevalence over time according to policy type by estimating, for each registry, the ratio of prevalence in 1999-2001 to 1989-91 and calculating the mean of such ratios (on a $\log$ scale) for all registries in countries with similar policy types (as introduced by 1999), using standard random effects meta-analysis techniques. ${ }^{3}$ In the United Kingdom and Ireland we found a significant overall mean reduction in the prevalence of neural tube defects in 1999-2001 compared with 1989-1991 (32\% (17\% to $44 \%))$, continuing a trend that preceded policies of folic acid supplementation. Registries in other countries with a policy of raising periconceptional folate status (by supplementation or dietary means) introduced by 1999 had a mean reduction in prevalence of $17 \%$ ( $44 \%$ reduction to $4 \%$ increase), whereas registries from countries with no policy by

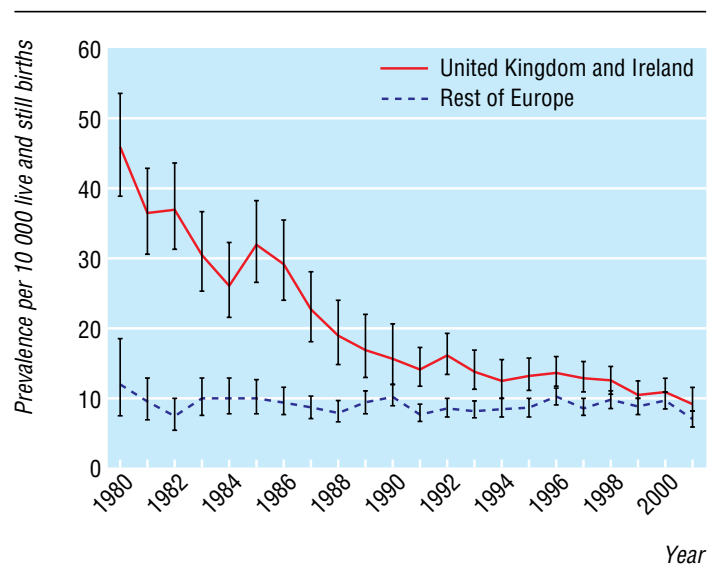

Prevalence of neural tube defects in the United Kingdom and Ireland and in other European countries, 1980-2001, adjusted for registry (prevalence $=$ total neural tube defect cases (live births + fetal deaths from 20 weeks' gestation (including stillbirths) + terminations of pregnancy)/(total live births + stillbirths))

1999 showed a mean reduction of $9 \%(26 \%$ reduction to $12 \%$ increase). ${ }^{3}$

\section{Comment}

The prevalence of neural tube defects in Europe has not declined substantially in the past decade despite national policies of folic acid supplementation in half the countries. The prevalence in the United Kingdom and Ireland fell by 32\% continuing a stronger pre-existing trend and remains slightly higher than overall European levels. These data suggest that policies simply recommending periconceptional supplementation of folic acid in planned pregnancies are not effective enough. Many women may not receive or respond to health promotion messages stressing the need to commence supplementation preconceptionally, or may remain unaware that dietary modifications are unlikely to achieve sufficient folate intake, ${ }^{\mathrm{w1}}$ and a large proportion of pregnancies in most countries are unplanned. ${ }^{2}$ Folate status of most women of childbearing age could be raised by fortifying a staple food with folic acid, ${ }^{4-5}$ which would also help to reduce socioeconomic inequalities in the prevalence of neural tube defects. Health effects of supplementation and fortification should be monitored, and policies should be reviewed periodically in light of the findings. The potential for preventing neural tube defects in Europe by raising folate status is still far from being fulfilled, ${ }^{1}$ and it is unacceptable to continue to rely mainly on prenatal screening and termination to reduce the number of babies born with neural tube defects. ${ }^{2 \mathrm{w} 2}$

Information about the figure and references $w 1$ and w2 are on bmj.com 


\section{What is already known on this topic}

Periconceptional folic acid supplementation can prevent most neural tube defects if widely used

Supplementation must begin before conception for it to be effective

\section{What this study adds}

Lack of a substantial decline in neural tube defect prevalence in Europe since 1991 shows that the potential for preventing neural tube defects is still far from being fulfilled

Periconceptional supplementation and fortification of staple foods is needed to reach all women before conception and to prevent widening of socioeconomic inequalities

Contributors: $\mathrm{AB}$ designed, did, and interpreted the statistical analysis and drafted the paper. LA designed the survey, gathered information, provided neural tube defect data, interpreted the results, and drafted the paper. HD designed the survey and statistical analysis, interpreted the results and drafted the paper. BA designed and interpreted the statistical analysis and drafted the paper. All the above authors are guarantors. Members of the Eurocat Folic Acid Working Group, who were involved in design, completion and interpretation of survey, development of Eurocat recommendations, contributed neural tube defect data to the Eurocat central database and commented on drafts of the paper: Marie-Claude Addor, Nicola Armstrong, Ingeborg Barisic, Andrea Berghold, Paula Braz, Elisa Calzolari, Marianne Christiansen, Guido Cocchi, Anne Kjersti Daltveit, Hermien De
Walle, Grace Edwards, Miriam Gatt, Blanca Gener, Yves Gillerot, Romana Gjergia, Janine Goujard, Martin Haeusler, Anna LatosBielenska, Robert McDonnell, Amanda Neville, Annukka Ritvanen, Christine Rösch, and Volker Steinbicker. Maria Loane extracted the data from the Eurocat central registry database. The following Eurocat registry leaders contributed data to the Eurocat central database: Sebastiano Bianca, Fabrizio Bianchi, Patricia Boyd, Catherine de Vigan, Maria Feijoo, Ester Garne, Lorentz Irgens, David Lillis, Maria Luisa Martinez-Frias, Carmen Mosquera Tenreiro, Vera Nelen, Annette Queisser-Luft, Elisabeth Robert, Gioacchino Scarano, Claude Stoll, David Stone, Romano Tenconi, and David Tucker.

Funding: Eurocat is supported by the EU Commission Public Health Directorate Public Health Programme.

Competing interests: None declared.

Ethical approval: All registries have the ethics approval appropriate to their national and local ethics guidelines.

1 MRC Vitamin Study Research Group. Prevention of neural tube defects: results of the Medical Research Council vitamin study. Lancet 1991:338:131-7.

2 Eurocat Folic Acid Working Group. Eurocat Special Report: prevention of neural tube defects by periconceptional folic acid supplementation in Europe. University of Ulster: Eurocat Central Registry, 2003. www.eurocat.ulst.ac.uk/pubdata/folic\%20acid.html (accessed 7 Feb 2005).

3 Busby A, Abramsky L, Dolk H, Armstrong B, a Eurocat working group. Eurocat Special Report annex: preventing neural tube defects in Europe: a missed opportunity. University of Ulster: Eurocat Central Registry, 2005.

4 Honein MA, Paulozzi LJ, Mathews TJ, Erickson JD ,Wong LY. Impact of folic acid fortification of the US food supply on the occurrence of neural tube defects. JAMA 2001:285:2981-6.

5 Persad VL, Van den Hof MC, Dube JM, Zimmer P. Incidence of open neural tube defects in Nova Scotia after folic acid fortification. CMAJ 2002:167:241-5

(Accepted 27 January 2005)

\section{The mystery of the milky effusion}

A 59 year old man was admitted to our cardiac surgical intensive care unit after a third operation on the mitral and aortic valves. His previous operations had been six months before. All three surgeries were done via a median sternotomy, and the left pleural space was never opened during the operations.

The postoperative recovery was initially uneventful. The day after surgery the patient was extubated, and the chest drains removed. The next day, however, we noticed a reduced air entry in the left lower zone of the chest, and a chest $\mathrm{x}$ ray showed some haziness in the left lower zone, consistent with a collection of fluid in the left pleural space. A diagnostic aspiration with a 14 gauge venous cannula in the seventh intercostal space in anterior axillary line produced a whitish fluid that looked uncannily like fresh milk.

Laboratory tests confirmed that the fluid was chyle, and the absence of vegetable particles ruled out stomach contents. Chylothorax due to excessive sternal retraction causing injury to the thoracic duct, though rare, is not unknown. The lab categorically labelled the aspirate as chyle and not as milk from the stomach. However, a vigilant attending nurse noted that the patient had drunk $250 \mathrm{ml}$ of milk only 30 minutes before the aspiration. Meanwhile, the sample in the kidney tray showed curdling after two hours.

Because of persistent haziness on the chest $\mathrm{x}$ ray, we took a second aspirate at the sixth intercostal space the next day. This produced serosanguinous fluid rather then chyle, and we inserted an intercostal drain, which drained $600 \mathrm{ml}$ in the first 24 hours. We removed the drain after 48 hours and ruefully concluded that the "chyle" of the first sample must have been due to transthoracic stomach aspiration.
We had all got carried away by the milky aspirate and had considered the exotic possibility of chylothorax from repeat surgeries and extensive retraction of the sternum. Even in a busy cardiac surgical intensive care unit that treats some 1200-1300 cases of open heart surgery a year, a simple situation can be made complex by incorrect interpretation of laboratory results.

The milk didn't curdle in the patient's stomach immediately because of the high $\mathrm{pH}$ of his gastric juice after routine use of $\mathrm{H}_{2}$ blockers. The pathologist didn't see any vegetable matter in the sample, but the patient had taken only clear fluids for the previous 24 hours. Aspiration was done with the patient in a semi-recumbent position (because of his postoperative status), with a full stomach $(250 \mathrm{ml}$ of milk), and during expiration. Clearly, the needle went through the chest wall, pleural space, diaphragm, and peritoneal space and reached the stomach.

Some lessons can be learnt from this. Always try to do an aspiration with the patient in the proper position, bending forward against a table, in full inspiration, and, if possible, with an empty stomach. Investigations go hand in hand with clinical inputs and with the patient status. Milk and chyle can have similar physical characteristics and chemical composition, and interpretation can depend on the feedback by the clinician to the laboratory. Chylothorax is a debilitating and serious condition, whereas transthoracic stomach aspiration is a technical error that has no complications but can lead to a vexed clinical situation that can confuse even the most experienced clinician. This was a fantastic learning experience that has made us wiser and much more sober.

Rajnish Duara resident, department of cardiovascular and thoracic surgery, Sree Chitra Tirunal Institute for Medical Sciences and Technology, Thiruvananthapuram,India (rajnishduara@rediffmail.com) 